\title{
Library Future Shock: The Microcomputer Revolution and the New Role of the Library*
}

\section{Alan E. Guskin, Carla J. Stoffle, and Barbara E. Baruth}

Dramatic advances in information-processing technology, especially in regard to microcomputer software and hardware, have broad implications for higher education in general and academic libraries specifically. This paper addresses the importance of planning for the integration of this technology into the campus and proposes a role for academic librarians that, if accepted, would bring academic librarians to the center of campus policy discussions in the future.

he future role of the library may be the most important issue for the present generation of educational leaders if the intellectual life of the university is to be adequately protected for this and future generations of students and faculty. University libraries are at a critical crossroads. Pressures emanate from a number of diverse sources: the financial difficulties of universities, the decay of physical facilities, the economics of book publishing, the inflationary cost increases in periodicals and serials, and the surge in computer technology that is changing the nature of information retrieval and information technology.

The academic library has in the past often been referred to as the center of the university. Yet the role of the library has been more symbol than reality for many years. Although it may be physically located at the heart of the campus or sym- bolically placed there in the words of the college catalog or even the university president, the day-to-day reality for libraries and librarians has been much different. On most, if not all campuses, the libraries are discussed in depth only when something goes wrong or when the realities of inflation continue to ravage a dwindling materials budget. The library is not a center of policy discussions and librarians are, on the whole, not an influential lot. Yet, it is possible that this will change given how information will be processed, retrieved, and disseminated in the immediate future. While it would have been desirable in the past for the library to be a central concern of academic policymakers, it will be essential in the future for libraries to be such.

One of the critical issues facing universities, namely, the difficult fiscal situation, will most certainly bring the library to the front and center of university policy con-

${ }^{*}$ A revision of a paper presented by Dr. Guskin at the dedication of the Bowling Green University Library.

Alan E. Guskin is chancellor, Carla J. Stoffle is assistant chancellor for educational services, and Barbara E. Baruth is head of technical services, Library/Learning Center, all at the University of Wisconsin-Parkside. 
cerns. Inflation continues to eat away at the core of the physical facilities and instructional equipment and materials, and this is nowhere more apparent than in university libraries. For example, from 1977 to 1981 , the average cost of a book increased 32.6 percent. ${ }^{1}$ From 1977 to 1981 , the average cost of periodicals increased an incredible 59.1 percent. $^{2}$ Assuming a 60-40 ratio of periodicals to books, in order to purchase the same number of books and periodicals in 1981 that was bought in 1977 , the library materials budget would have had to increase by 49 percent. In dollars, a university that spent $\$ 500,000$ in 1977 would have had to spend $\$ 745,000$ in 1981 to stay even. During this same period, many university budgets, excluding salaries, have, at best, been static. The result at many universities that pride themselves on having a good library is that even substantial increases in the library materials budgets have been inadequate. As a result, a decrease has occurred in book purchases. Also, periodicals and serials subscriptions have been carefully reviewed, some titles eliminated entirely, and others replaced in part by the introduction of alternative sources such as through computer retrieval systems (online bibliographic data banks and electronic publishing services), and in part by a heavier reliance on resource sharing. Because of fiscal problems and faculty outcry against periodical cuts, the library has become a serious concern of policymakers.

A second critical matter that university policymakers must face that will have a direct impact on the library is the microcomputer revolution and the increased demand for computer use. There has been a continuing increase in computer use over the last decade as faculty apply this technology to more and more research areas and as engineering and business schools grow in students, faculty, and use of the new technologies. Much of the increased computer use generally has been focused on mainframe computers and sophisticated users who, utilizing available computer power, figure out ways to work with their similarly hardware-oriented computer center colleagues to solve their computing needs.
The introduction of microcomputers has significantly altered these patterns; it has changed how people think about computers and how they can be utilized to fill their needs. Now unsophisticated users, who cannot program and who do not really understand the internal operations of a computer, are able to use the power of the new technology in ways unthinkable just three years ago.

It is not only the development of highpowered microcomputer hardware that has really made the difference. Rather, the major change is the result of what is called applications software, the programs on floppy disks that tell the computer what to do. Now even an unsophisticated user can place a disk in a disk drive, turn on the microcomputer and video monitor, and, with a little bit of self-education, use a sophisticated word processing system or a bookkeeping-type spreadsheet program for budget forecasting and continuous monitoring of budgets. It is no longer necessary to know how to program, only to follow instructions and to be willing to spend a little time practicing. The best analogy to reflect this change in the use of computers is the automobile. In order to drive a car, you don't have to know how an internal combustion engine works or how to fix the engine; what you must know is how to put the key in the ignition and how to drive the car-a skill that, while complicated at first, is easily learned by almost everyone. Similarly, with microcomputers, it is not necessary to know how to program a computer or to understand the computer's architecture. What the user must do is, after learning to turn the machine on, be able to identify an appropriate program, and to follow the instructions for operating the program.

A major issue for the university is how to respond to the microcomputer revolution. The effect of the fierce competition among microcomputer companies, the ensuing media coverage, and the increased sophistication of nontechnical faculty and students (that is, those who are not in science, engineering, or business) has put pressure on universities to respond in some way. The wonders of the microcomputer are proclaimed loudly and 
widely. And there are wonders! But, as in all cases, the race to sell machines has created a sensational atmosphere that overestimates the potential benefits. Microcomputers can be exceptional tools in supporting the educational process as well as providing increased access to information for research, planning, and decision making. They are significant tools for universities. Policymakers should and must determine how best to utilize them. Should all students be required to learn how to program computers? How should universities provide students with access to microcomputers? Should all students be required to own them? Or should the university view the access to microcomputers like access to all other information technology?

Universities must come to terms with these questions and, in doing so, must involve policy-oriented administrators, faculty, and staff as well as sophisticated computer-oriented experts. Unfortunately, up to this point in time, many policy decisions have not involved universitywide constituencies and have not been based on the realities of the changing computer hardware and software, especially as it relates to microcomputers. The result has been that a growing number of universities have developed either a computer literacy requirement based on learning programming, or only offer students who are interested in learning about how to use microcomputers programming courses.

One outcome of these developments has been a massive increase in the number of computer programming courses. Another is that students who merely wish to use specific microcomputer packages are discouraged and/or dissuaded from further involvement because they do not have the skill or interest in programming to stick with the courses.

Yet, it is becoming clear to many that computer programming is a skill that will not be necessary or may not even be very desirable for all but sophisticated technical people. A recent Wall Street Journal article states that there seems to be a growing reaction against computer programming courses among university professors and quotes a Stanford researcher as saying the "educational establishment has overreacted.",4 The column also quotes a professor at the University of Houston as saying that the "need for much of this [courses in programming] will disappear soon, and some of it is unnecessary now. Making computers easier for novices to use is one of the principal thrusts of computer design. As a result, in the future, less and less training will be needed to work with the machines." 5 Sar Levitan, a labor economist and professor at George Washington University, states, "It doesn't make sense when futurists say that we'll all have to understand computers. We'll need a few specialists, of course, experts to design them, technicians to repair them. But most people won't have to know any more about computers than they know about telephones or x-rays. They'll just use the technology. ${ }^{\prime \prime 6}$ Finally, an information technology expert, Marc Tucker, concludes, "The computer is a powerful tool, and courses should concentrate on applications of the tool, in ways that extend the student's intellectual power. Students need to learn how to use data, to use work processors, and spread sheets. Programming is not what it's all about."'7

Today, microcomputers are not highly specialized pieces of equipment that should be accessible only to the expert. Because of their ability, through myriad software programs, to serve as powerful educational tools, they must be treated by educational policymakers as part of the academic support services of a university available to everyone, much as other resource materials are treated, e.g., videotapes, films, books, and periodicals. The question of how they will become integrated into courses-and they will become integrated into most-will be a decision of an individual faculty member who has become somewhat knowledgeable about how students can best use microcomputers to learn and apply course material.

Indeed, there is a real revolution in information technology that has been sharply accelerated by the introduction and rapid development of microcomputers. The information technology revolution not only can help assuage the twin 
scourges of inflation and fiscal constraints, but offers libraries and librarians the opportunity to assume significant new roles of informational and educational leadership on their campuses. How does all this relate to our libraries and librarians?

1. The computer, especially the microcomputer, is an informational technology tool and it is the responsibility of libraries to provide information. Terminals or microcomputers acting as terminals provide ease of access and decentralized access to an increasing variety of networks of information. Microcomputers in combination with the vast storage potential of easily duplicated optical video disks promise to further decentralize access to information in electronic form. In addition, the microcomputer has the added ability to download information and data from such information sources, allowing a user to store, edit, and analyze it easily. Given the proliferation of commercial and academic databases, the library can become more active in linking users to data and thereby further enhance its historic role as the primary purveyor of information in the university.

2. Electronic publishing could become important to many areas of scholarly research where hard-copy publishing is becoming more and more unprofitable. The combination of easy access and the capability of making hard copies, where necessary, with high-speed printers at sharply reduced costs could lead to significant changes in future access to research reports, including a great improvement in time lag between research, publishing, and information availability. In fact, in these situations libraries themselves, particularly research libraries, could become the publishers of studies that have very limited readership. While this would be a wholly new function for academic libraries, it might evolve because of the needs of scholars. However, extremely important issues must be worked out: issues of peer review (refereeing), royalties, and how to develop the necessary networks between universities.

3. In the next few years, ability to utilize microcomputers in schools and workplaces may be almost as common as knowing how to drive a car. People will be able to learn how to utilize such powerful information technology in short courses. In fact, much more time will be spent selecting and learning how to use specific programs than learning about the computer itself. As a result, the library may very well, and some have already, become the center for short workshops on the use of microcomputer software applications, much as many libraries have become the primary instructional unit for teaching people how to utilize the numerous bibliographic and information resources available in the library. In addition, as faculty increasingly integrate the use of specific software applications in their courses, making these programs and microcomputers available in the library for classroom assignments will be the future equivalent of placing books on reserve.

The key to the proper application of the microcomputer as an educational tool, like that of a textbook, rests with the interest and knowledge of the individual faculty member teaching a particular course and with the training and time to learn available to faculty members. ${ }^{8}$ The library could be the primary focus for faculty development in this area. As librarians work with faculty in new information technology areas, such as online database searching, and in course-integrated bibliographic instruction settings, it is a natural extension for them to help faculty develop their skills in microcomputer applications.

5. To facilitate campuswide access and use of the microcomputer, the library could and should maintain strong collections of microcomputer software and elaborate microcomputer labs that will enable students to use them as they would other instructional materials.

But why the library rather than the computer center? Answers to this question require an appreciation of the needs of information seekers, the role of librarians in fulfilling these needs, and the role of the new information technology. Basically, the principal role of the library, and especially the reference librarian, has been to 
provide a link between the user and information resource. To accomplish this requires an ability to define the information problem, to understand and be sensitive to the needs of the individual student or faculty member, to be knowledgeable about available information sources, and to know how to gain access to them in a reasonable time period.

In the last decade many librarians, realizing through painful experience students' ignorance of bibliographic sources, have developed bibliographic instruction programs using materials such as workbooks at the freshman level to introduce students to the library and its bibliographic sources. Even more recently, programs and materials have been developed for specific disciplines to enable students to avoid the time-consuming trial-anderror method of learning how to search out needed information. In both these instances, reference librarians working closely with faculty have become instructors for a number of class periods in introductory English classes and research methods courses in the academic disciplines in order to facilitate a student's use of library resources. In providing these services, librarians have become an important component of the instructional process for developing skills in the use of new and old information sources. They, themselves, have developed skills in instructing students and faculty on these matters as well as having maintained their traditional roles of being primary information resources for faculty and students.

Further, librarians-at least the effective ones-in their efforts to serve the needs of faculty members and their disciplines, have developed an understanding of faculty information needs across the campus through interviews with faculty, working with faculty on collection development, performing online database searches, etc. In fact, it is probably true that the staff of the library have a better sense of the intellectual needs of the entire faculty, or any significant segment, than any other group on a university campus. This universitywide perspective has enabled them to plan the university's collection needs and will enable the library to effectively serve the university as the faculty become more attuned to the power of computer and microcomputer applications.

In the last few years, libraries and librarians have had to gain sophistication in the use of computers in order to provide access to the growing wealth of computerized databases and to automate library operations. Librarians have shown the potential to become the central campus resource for the new information and communication technology.

Beyond the above, librarians have developed specific skills that could enhance the library's role as the campus center for information processing. Among these are the following:

1. Librarians tend to be people-oriented and have professional experience in responding to the information needs of the faculty and students.

2. Librarians are skilled in information retrieval activities and changing technologies, even though they will obviously need additional training to become sophisticated in all aspects of computer searching and computer networking.

3. Librarians are information specialists, trained to be concerned with information acquisition, dissemination, and use.

4. Librarians are managers; they are involved in a host of administrative activities including purchasing, work-force analyses, and managing large numbers of part-time and full-time people. The library is the only campus unit organized to handle the information needs of a large number of users in an orderly, systematic way. The librarian's ability to manage will be important in administering new information technology and understanding staff needs.

5. Librarians tend to be responsive to changing university priorities.

The capability of the library to be an effective resource in information processing is further enhanced by the fact that it is a low-threat environment in which all students and faculty are continuously interacting to fulfill their information needs. By the placement of microcomputers in the library, it is conceivable that a relatively 
high-threat educational tool can be neutralized and thereby become more accessible, especially to the nontechnical students and faculty.

Although the logic of locating a universitywide information function, albeit a new technological one, in the library is compelling, what about the logic of expanding the function of the computer center to meet the microcomputer revolution? While the staffs of computer centers are sophisticated about the technology itself, the orientation of most computer center professionals is to the use of hardware-to make sure it operates effectively and to provide machine links of the user to the mainframe. Such individuals are not concerned with training or practice in information dissemination and use, but are concerned with data-its storage and manipulation. Also, computer technicians tend to be not highly skilled in interpersonal relations, unconcerned about the application problems of unsophisticated users, and unknowledgeable about teaching users how to access or use outside information sources. In significant ways, the major revolution in microcomputer software applications, which has focused on the unsophisticated user, has left many professionals in computing on the sidelines. In addition, many mainframeoriented computer centers (and highly expert computer-oriented faculty) have tended to resist the introduction of microcomputers for the general user.'

The computer center, with its highly sophisticated and powerful mainframe computers and related equipment, is an essential component in the operation of a university; it is a utility that serves the data processing needs of faculty and students. It often serves as a central point in linking up the ever-increasing number of microcomputers to internal and external networks. But it does not seem to be the appropriate university unit for providing large-scale access to microcomputers, for instructing faculty and students about the potential applications of microcomputers, or for providing linkage between the information needs of the unsophisticated user and the available information source-whether that be a simple pro- gram, an internal computer network where data can be stored and processed or information obtained, or an external computer network.

Change does not come easily nor is it patently predictable, and the introduction of the powerful new information technology is no different. Inherent in the new technology are the human foibles of overenthusiasm, straight-line projections based on limited experience, and the byproducts of the fierce competition between commercial vendors. We are already experiencing projections of too much change, some of which smacks of the absurd, some of which is just plain overzealousness. No matter what the enthusiasts proclaim, there will still be numerous hard-copy books, for there still is money to be made in the publishing of books and convenience in using them. But just as obvious, limited-circulation scholarly texts will no longer be published in hard copy; it doesn't make economic sense to the publisher or the library, nor is it particularly helpful to the scholar who would prefer having greater access electronically to numerous limited-circulation scholarly monographs than having limited access to a few hard-copy books that a publisher was somehow willing to print.

In closing, several issues need to be addressed. First, judicious use of the microcomputer must be made in the learning process. Educators must be cynical about its role as a panacea for educational problems and highly analytical in the best ways to use it as an educational tool. It is an important educational tool but it is just that. It must be remembered that the microcomputer should augment facultystudent relationships, not replace them.

Second, educators must be concerned about who controls information networks. This is one of the most critical issues that libraries and universities must face. How can open access to the world of information be maintained? Will commercial vendors stake out the domain before universities can? What implications do proprietary rights have for scholarly and bibliographic ventures that have traditionally been open to all through the role played by academic libraries? Will com- 
mercial vendors balkanize the information networks? How will institutions and/or individual scholars be able to afford access? These and related issues must be dealt with very soon or universities will find themselves afloat in a commercially competitive world. Even though the cost of development may be great, the sheer power of larger computers and computer networking has made possible the accumulation of information inconceivable a few years ago. At the same time the presence of microcomputers of all shapes and sizes that can gain access to these information networks has created the potential for commercially viable information sources that could limit the freedom of access so common to academic life. The irony might be that just at the time that the technological tools have been created to harness the enormous growth of information of the last three decades, universities may lose the ability to offer open access to the information produced directly and indirectly by their faculty and staff. University educators, faculty, and librarians must be the watchdogs of the free flow of information.

Whichever way these issues are resolved, the library and the increasingly technologically sophisticated librarians can and should be at the center of the major developments in the use of the new in- formation and communication technology in university life and, therefore, intimately involved in university policy development. The basic challenge for librarians is whether they are prepared to reeducate themselves, whether they are prepared to take the risks inherent in being at the center of major new developments, whether they are capable of entering into the political dialogue of university policy-making that will determine the allocations of resources regarding new information and communication technology. Some would say that it is safer to stay on the edges of the policy debates, to quietly learn about the new technology and slowly adjust to it, thereby avoiding new responsibilities inherent in being the primary instructional unit for microcomputers and the service unit for computers generally. It is safer but so is the quill pen. The problem is that if librarians take this attitude, events will pass them by. We need a strong academic library system with creative and energetic librarians who are willing and excited about taking the risks necessary to move the library of the future into a central role in the day-to-day life of the university. It is essential for the future health of our universities-and our libraries!

\section{REFERENCES}

1. Bowker Annual of Library and Book Trade Information (New York: Bowker, 1982), p.400.

2. Ibid, p. 397.

3. Judith Axler Turner, "Many Colleges Limit Students' Use of Central Computers for Writing," Chronicle of Higher Education 27, no.15: 1, 16 (Dec. 7, 1983).

4. Richard A. Shaffer, "Courses in Computer Literary Beginning to Draw Bad Marks," Wall Street Journal Sept. 16, 1983.

5. Ibid.

6. Ibid.

7. Ibid.

8. Robert Gillespie and Deborah Dicaro, Computing and Higher Education: An Accidental Revolution (Seattle, Wash.: Washington Univ., 1981), p.24.

9. Turner, p.16. 